\title{
Electrochemical Impedance Spectroscopy (EIS) Study of Modified Type- 316L Stainless Steel (SS) as an Effective Biomaterial for Orthopedic Implant Applications
}

\author{
Sharif Hussein Sharif Zein* and Muhammad Faiq Abdullah
}

School of Chemical Engineering, Engineering Campus, Universiti Sains Malaysia, Seri Ampangan, 14300 Nibong Tebal, Seberang Perai Selatan, Pulau Pinang, Malaysia

For centuries, metals and alloys have been used in substitution for anatomical structures owing to their extraordinary mechanical properties [1]. Type 316L Stainless Steel (SS) is known to be widely used for implantation purposes in orthopedic surgery due to its corrosion resistance, effective cost and superior mechanical properties $[1,2]$. However, several incidences of failures involving type 316L SS have been occurred which released the metal ions into tissues [1] and blood stream surrounding the implants, thus causing histological changes of the local tissue by direct toxic effects or local hypersensitivity reaction [3]. It is highly probable that electrophoretically deposited Multiwall Carbon Nanotubes (MWCNTs) and Hydroxyapatite (HA) on type 316L SS could minimize this limitation, and further investigation of its corrosion behavior using in vitro electrochemical techniques $[1,4]$ may confirm the acceptability of modified SS as an effective biomaterial to be used as orthopedic implants.

An ideal orthopedic implant should possess biocompatible, osteoconductivity [5], superior mechanical properties [6-8] and excellent corrosion resistance to physiological environments of the human body [1,9]. Different electrochemical techniques for evaluation of corrosion behavior have been studied extensively included Electrochemical Impedance Spectroscopy (EIS), cyclic potentiodynamics polarization and Open Circuit Potential (OCP) studies [2]. EIS is a useful approach to monitor in situ electrochemical changes [10] and to develop understanding of the physical process occurring at the electrode-electrolyte interface [11-13]. EIS study was carried out based on an appropriate circuit model in order to fit the experimental data to equivalent circuit model parameters, whereas each parameter would represents macroscopic physical quantity which contributing to interface impedance [11]. An equivalent circuit was selected to represent the electrochemical behavior of metals implants that have been coated with an unsealed porous film [14]. The equivalent circuit consists of solution resistance of the electrolyte (experimental human body fluid solution), $\mathrm{R}$, capacitance of non-defective coating layer, $\mathrm{C}_{\mathrm{p}}$, charge transfer resistance of electrolyte's penetration through pinholes, $R_{p}$, polarization resistance of substrate, $R_{b}$ and electrical double-layer capacitance at substrate/electrolyte interface, $C_{b}[4]$. This physical model of the electrochemical reactions that occurred at the electrodes is important to interpret the electrochemical behavior of the metal implants from EIS spectra [15].

Certain amount of current density is necessary to generate activity in stimulation process which resulted in interface impedance of the metal implants [4]. The equivalent model comprises an interface capacitance, shunted by charge transfer resistance and in series with solution resistance [16]. Then, a theoretical equation has been used to determine the interface capacitance impedance and solution resistance in order to confirm the results that correspond well with the fitted parameter values, hence validating the model equations [4]. Impedance behaviors of the metals implants could be expressed either in a Bode plot of logarithm of impedance modulus $(|\mathrm{Z}|)$ and phase angle $(\Phi)$ as a function of logarithm of frequency or in a Nyquist plot of Z" $(\omega)$ as a function of $Z^{\prime}(\omega)[14,17]$. The Bode plots of logarithm total impedance $|Z|$ vs. frequency for uncoated SS and coated samples of SS/MWCNT-OH are shown in Figure 1(a) and for uncoated SS and
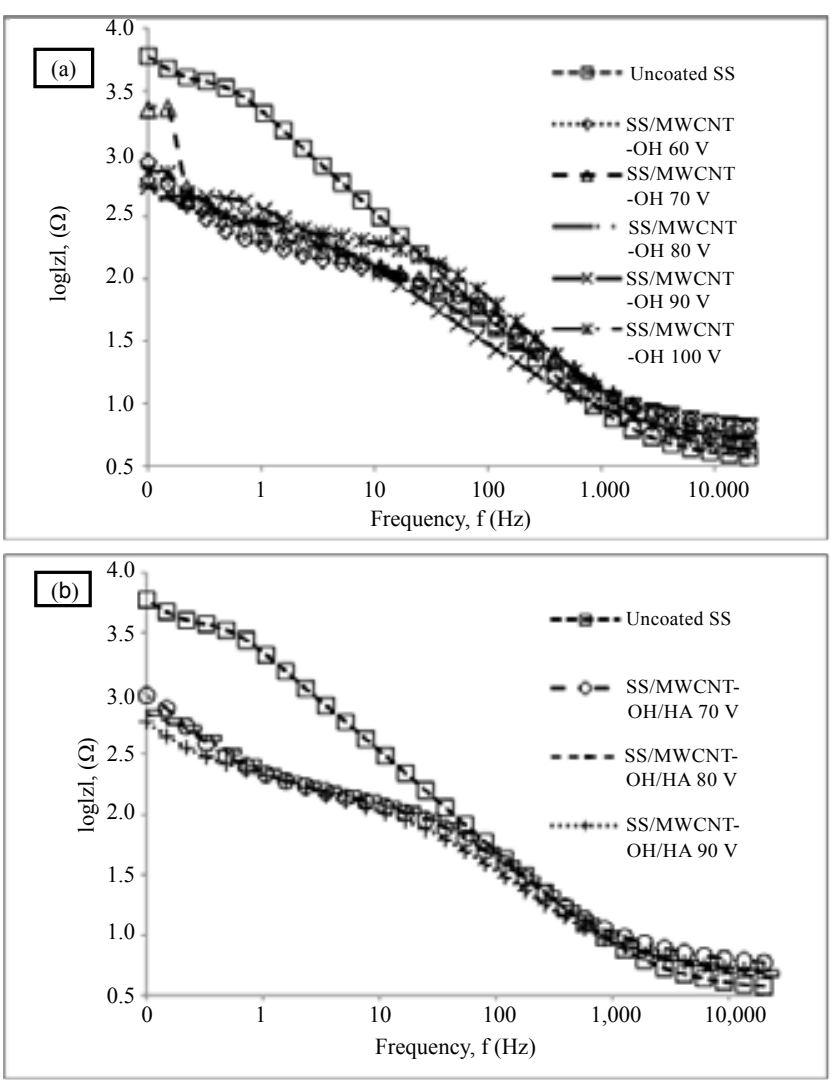

Figure 1: Bode plots of logarithm total impedence $|z|$ vs. frequency of (a) uncoated SS and coated samples of SS/MWCNT-OH and (b) uncoated SS and coated samples of SS/MWCNT-OH/HA.

*Corresponding author: Sharif Hussein Sharif Zein, School of Chemical Engineering, Engineering Campus, Universiti Sains Malaysia, Seri Ampangan, 14300 Nibong Tebal, Seberang Perai Selatan, Pulau Pinang, Malaysia, E-mail: chhussein@eng.usm.my

Received April 27, 2012; Accepted April 27, 2012; Published May 02, 2012

Citation: Zein SHS, Abdullah MF (2012) Electrochemical Impedance Spectroscopy (EIS) Study of Modified Type-316L Stainless Steel (SS) as an Effective Biomaterial for Orthopedic Implant Applications. J Nanomed Nanotechol 3:e108. doi:10.4172/2157-7439.1000e108

Copyright: ( 2012 Zein SHS, et al. This is an open-access article distributed under the terms of the Creative Commons Attribution License, which permits unrestricted use, distribution, and reproduction in any medium, provided the original author and source are credited. 
Citation: Zein SHS, Abdullah MF (2012) Electrochemical Impedance Spectroscopy (EIS) Study of Modified Type-316L Stainless Steel (SS) as an Effective Biomaterial for Orthopedic Implant Applications. J Nanomed Nanotechol 3:e108. doi:10.4172/2157-7439.1000e108

coated samples of SS/MWCNT-OH/HA as in Figure 1(b). Bode plots were used to estimate the impedance parameters in equivalent circuit model, thereby indicates the corrosion behavior of modified SS after immersed in Phosphate Buffer Saline (PBS) solution. The decrease of polarization resistance and coating layer capacitance imply that the coating layers of MWCNT-OH and HA tend to protect SS by reducing the penetrations of anions from PBS solution $[1,14]$, hence improving corrosion resistance of the modified SS [1].

Cyclic potentiodynamic polarization study is carried out when the susceptibility of metal implants to localized corrosion need to be addressed [18]. Pitting potential, $\mathrm{E}_{\mathrm{b}}$ and pit protection potential, $\mathrm{E}_{\mathrm{prot}}$ could be determined from cyclic potentiodynamic polarization curve [19] as these parameters are needed to evaluate pitting corrosion of metal implants [2]. Direct measurement of pit propagation mechanisms is proportional to the area under cyclic potentiodynamic polarization curve $[2,19]$, as larger area of hysteresis loop indicates higher rate of pits formation [1]. OCP measurement provides simple evaluation of corrosion behavior including oxide film formation and metal implants passivation in experimental body fluid environment as a function of time $[2,20]$. The increasing potential in positive direction achieving steady state indicates the metal implants remains protective $[17,20]$ while potential drops toward negative direction implies no film formation or break in the film [17] due to dissolution of carbon, ferum and oxides particles from metal implants surface when immersed in experimental body fluid solution [4]. Cyclic potentiodynamic polarization and OCP studies are able to provide useful evaluation of corrosion behavior [20] and pitting corrosion resistance [19] of metal implants, however, these electrochemical techniques provide less information of adsorption behavior and interactions of body fluid environment to metal implant surface [21], thus leaving EIS study as suitable technique to investigate the acceptability of modified SS to be used as orthopedic implants.

So, is the corrosion behavior study of the modified SS by EIS is enough to confirm its acceptability as an effective orthopedic implants? While in vitro EIS study have indeed able to show lower polarization resistance and coating layer capacitance of modified SS, more quantitative determination of corrosion products need to be performed in order to investigate their adverse effects on tissues surrounding the implants [19]. Hence, both in vitro cell-culture experiments and clinical retrieval studies [22] in conjunction with in vivo biological investigations of modified SS need to be investigated to ensure its continuous clinical applications in biomedical field.

\section{References}

1. Sridhar TM, Kamachi Mudali U, Subbaiyan M (2003) Preparation and characterisation of electrophoretically deposited hydroxyapatite coatings on type 316L stainless steel. Corros Sci 45: 237-252.

2. Mudali UK, Sridhar TM, Raj B (2003) Corrosion of bio implants. Sadhana (Academy Proceedings in Engineering Sciences) 28: 601-637.

3. Reclaru L, Lerf R, Eschler PY, Meyer JM (2001) Corrosion behavior of a welded stainless-steel orthopedic implant. Biomaterials 22: 269-279.

4. Franks W, Schenker I, Schmutz P, Hierlemann A (2005) Impedance characterization and modeling of electrodes for biomedical applications. IEEE Trans Biomed Eng 52: 1295-1302.

5. Ma J, Wang C, Peng KW (2003) Electrophoretic deposition of porous hydroxyapatite scaffold. Biomaterials 24: 3505-3510.

6. Boccaccini AR, Keim S, Ma R, Li Y, Zhitomirsky I (2010) Electrophoretic deposition of biomaterials. J R Soc Interface 7: 581-613.

7. Javidi M, Javadpour S, Bahrololoom ME, Ma J (2008) Electrophoretic deposition of natural hydroxyapatite on medical grade 316 L stainless steel. Materials Science and Engineering: C 28: 1509-1515.
8. Kaya C (2008) Electrophoretic deposition of carbon nanotube-reinforced hydroxyapatite bioactive layers on Ti-6Al-4V alloys for biomedical applications. Ceramics International 34: 1843-1847.

9. Ige OO, Umoru LE, Adeoye MO, Adetunji AR, Olorunniwo OE, et al. (2009) Monitoring, Control and Prevention Practices of Biomaterials Corrosion - An Overview. Trends Biomater Artif Organs 23: 93-104.

10. Rondelli G, Torricelli P, Fini M, Rimondini L, Giardino R (2006) In vitro corrosion study by EIS of an equiatomic NiTi alloy and an implant quality AISI 316 stainless steel. J Biomed Mater Res B Appl Biomater 79: 320-324.

11. López MF, Gutiérrez A, Jiménez JA (2002) In vitro corrosion behavior of titanium alloys without vanadium Electrochimica Acta, 47: 1359-1364.

12. Pan J, Thierry D, Leygraf C (1995) Electrochemical impedance spectroscopy study of the passive oxide film on titanium for implant application. Electrochimica Acta 41: 1143-1153.

13. Grahame DC (1952) Mathematical theory of the Faradaic admittance. J Electrochem Soc 99: 370-385.

14. Souto RM, Laz MM, Reis RL (2003) Degradation characteristics of hydroxyapatite coatings on orthopaedic TiAIV in simulated physiological media investigated by electrochemical impedance spectroscopy. Biomaterials 24 4213-4221.

15. Bard AJ, Faulkner LR (2001) Electrochemical Methods: Fundamentals and applications. Wiley 2: 10.

16. Randles JE (1947) Kinetics of rapid electrode reactions. Discussions Of The Faraday Society 1: 11-19.

17. Gurappa I (2002) Development of appropriate thickness ceramic coatings on $316 \mathrm{~L}$ stainless steel for biomedical applications. Surface and Coatings Technology 161: 70-78.

18. Schmutz P, Quach-Vu N-C, Gerber I (2008) Metallic Medical Implants Electrochemical Characterization of Corrosion Processes. Electrochemical Society Interface 1: 35-40.

19. Sivakumar M, Kamachi Mudali U, Rajeswari S (1994) In vitro electrochemica investigations of advanced stainless steels for applications as orthopaedic implants. Journal of Materials Engineering and Performance 3: 744-753.

20. Al-Mobarak NA, Al-Swayih AA, Al-Rashoud FA (2011) Corrosion behavior of Ti$6 \mathrm{Al}-7 \mathrm{Nb}$ alloy in biological solution for dentistry applications. Int J Electrochem Sci 6: 2031-2042.

21. Moisel M, de Mele MAFL, Müller WD (2008) Biomaterial Interface Investigated by Electrochemical Impedance Spectroscopy. Advanced Engineering Materials 10: $33-46$

22. Jacobs JJ, Gilbert JL, Urban RM (1998) Corrosion of metal orthopaedic implants. J Bone Joint Surg Am 80: 268-282. 